TECHNICAL NOTE

\author{
P. Taussky \\ D.F. Kallmes \\ H. Cloft
}

\section{Mathematic Analysis of Incremental Packing Density with Detachable Coils: Does That Last Coil Matter Much?}

\begin{abstract}
SUMMARY: Higher packing attenuation of coils in cerebral aneurysms is associated with a decreased recurrence rate. However, geometric relationships suggest that an additional coil may have very little effect on packing attenuation as aneurysm size increases. We mathematically evaluated the relationship between aneurysm size and incremental packing attenuation for coils currently available.
\end{abstract}

ABBREVIATIONS: ISAT $=$ International Subarachnoid Aneurysm Trial
$\mathbf{A}^{\mathrm{n}}$ neurysm recurrence is 1 of the main disadvantages of endovascular coiling relative to microsurgical clipping. ${ }^{1,2}$ Persistent aneurysm filling at the first angiographic follow-up in the ISAT study was noted in $34 \%$ of aneurysms treated by coil embolization and in $18 \%$ of those treated with microsurgical clip ligation. ${ }^{3}$ Lower occlusion rates are of clinical significance due to higher rebleeding risks in incompletely occluded aneurysms, ${ }^{4}$ according to the Cerebral Aneurysm Rerupture after Treatment study. ${ }^{2}$

The goal of endovascular therapy should be optimal angiographic coil occlusion of the aneurysm. ${ }^{5}$ Stable occlusion of the aneurysm is related to the coil packing attenuation because lower packing attenuation, especially if $<25 \%$, is associated with higher recurrence rates. ${ }^{6-8}$ Traditionally the endovascular approach to coil embolization involves 3 distinct stages: 1) "basket" or "framework" formation, 2) "filling of the basket" in an effort to pack the aneurysm volume, and 3) $\geq 1$ coil used in the final or "finishing" stage in an effort to maximize coil packing attenuation. Smaller and softer coils are typically used for this last step of coil embolization. ${ }^{5}$

While the use of small and soft coils at the finishing stage of aneurysm coiling is common practice, its impact on packing attenuation has not been analyzed in detail from a mathematic point of view. Because packing attenuation is commonly calculated as coil volume per aneurysm volume $\times 100 \%$, any relevant change in packing attenuation would require significant coil volume. In this study, we evaluated the effect of incremental coils on aneurysm packing attenuation.

\section{Technique}

We mathematically assessed 2 different aspects of aneurysmal packing attenuation ${ }^{1}$ : the length of coil needed to get incremental $5 \%$ packing in an aneurysm ranging from 2 to $20 \mathrm{~mm}$ in diameter by using a variety of commonly used coils ${ }^{2}$; and the length of coil needed to get $25 \%$ of coil attenuation packing of an aneurysm ranging from 2 to 20 $\mathrm{mm}$ in diameter, by using a variety of commonly used coils. The aneurysm volume was calculated under the assumption that aneu-

Received September 28, 2010; accepted after revision October 30.

From the Departments of Radiology and Neurosurgery, Mayo Clinic College of Medicine, Rochester, Minnesota.

Please address correspondence to Harry Cloft, MD, PhD, Departments of Radiology and Neurosurgery, Mayo Clinic College of Medicine, Rochester, MN 55905; e-mail: Cloft. Harry@mayo.edu

http://dx.doi.org/10.3174/ajnr.A2454 rysm shape was spheric, by using the following formula: Aneurysm Volume $=4 \times \pi \times(\text { radius })^{3} / 3$.

Coil volumes and coil lengths were calculated by using the following equation: Coil Volume $=\pi$ (radius) ${ }^{2} \times$ length.

The coil packing attenuation was calculated by using the following formula: Packing Attenuation $=($ coil volume $/$ aneurysm volume $) \times$ $100 \%$.

Incremental packing attenuation was determined for typical platinum coil diameters of 0.010 inch, 0.012 inch, and 0.015 inch and diameters of 0.022 inch for HydroCoil 10, 0.027 inch for HydroCoil 14, and 0.034 inch for HydroCoil 18 (MicroVention Terumo, Aliso Viejo, California).

Figures 1 and 2 depict the resulting need to get incremental 5\% packing in an aneurysm and the length of coil needed to get $25 \%$ of coil-attenuation packing. The Table summarizes the aneurysmal diameter at which a given coil achieves $1 \%$ packing attenuation per centimeter of coil length.

\section{Discussion}

Applying a 3-step endovascular coiling technique, with the last step involving "finishing" the previously "framed and filled coil basket" makes sense in an attempt to insert as many coils as possible to prevent possible compaction. ${ }^{6,8}$ Because of basic geometric principles, however, the length of coil material needed to achieve significant increase in packing attenuation increases exponentially with aneurysm size (Figs 1 and 2). Coils that add $<1 \%$ packing attenuation per centimeter could be considered to be inefficient for improving aneurysm treatment outcome (Table).

Because packing attenuation has been shown to have a direct relationship to the rate of aneurysm recurrence, the practice of maximizing the volume of coil used to treat each aneurysm certainly has a scientific foundation. However, given the increased expense of each incremental single coil as well as the increased risk of coil protrusion into the parent artery at the finishing stage of coiling, the additional benefit of using small coils toward the conclusion of treatment needs to be carefully considered. While there may be additional theoretic reasons by which finishing coils decrease the rate of recurrence (ie, better occlusion of the inflow zone), they often do little to increase packing attenuation in larger aneurysms. For example, adding an incremental $2 \times 8 \mathrm{~mm} 0.010$-inch coil to a 10 -mm diameter aneurysm adds slightly $<1 \%$ to the packing attenuation. Moreover, complications (both embolic and hemorrhagic) during coil embolization of intracranial aneu- 


\section{Length to get incremental $5 \%$ packing}

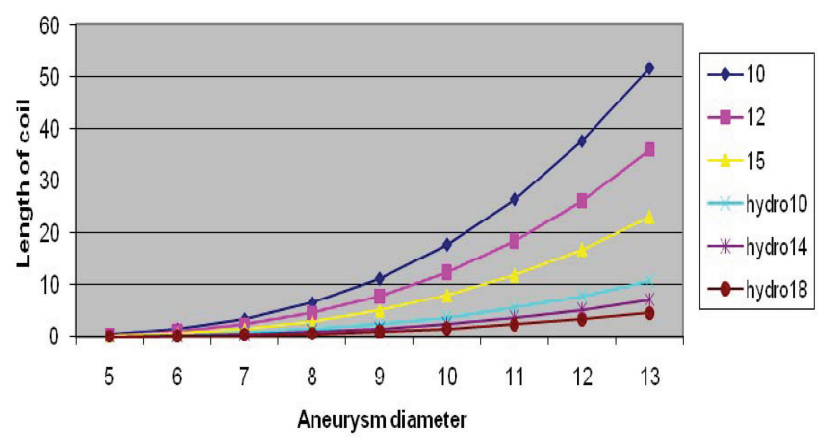

Fig 1. Length of coil (in centimeters) necessary for different coil types to achieve $5 \%$ incremental packing of aneurysms ranging from 0.5 to $1.3 \mathrm{~cm}$.

Length to get $25 \%$ total packing

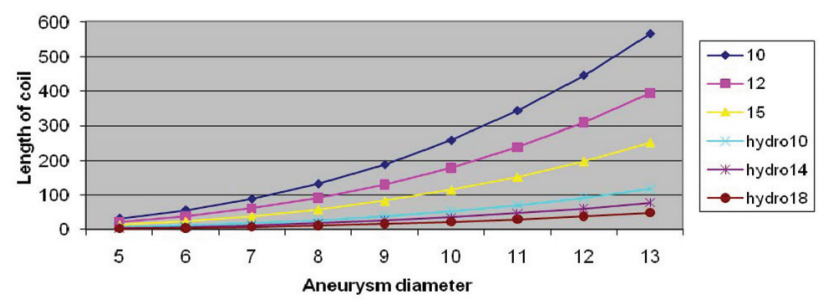

Fig 2. Length of coil (in centimeters) necessary for different coil types to achieve $25 \%$ packing attenuation in aneurysms ranging from 0.5 to $1.3 \mathrm{~cm}$ in diameter.

\section{Analysis of aneurysmal diameter at which a coil adds incremental} packing density of $1 \%$ per centimeter of coil

\begin{tabular}{lc}
\hline Coil Type & $\begin{array}{c}\text { Aneurysm Diameter } \\
\text { (mm) }\end{array}$ \\
\hline 0.010-Inch platinum & 4.6 \\
0.012-Inch platinum & 5.2 \\
0.015-Inch platinum & 6.0 \\
HydroCoil 10 & 7.8 \\
HydroCoil 14 & 9.0 \\
HydroCoil 18 & 10.3 \\
\hline
\end{tabular}

rysms are often observed in the final steps of the procedure. Another technique of exclusively using very small coils in a continuous fashion to achieve a packing attenuation of $\geq 25 \%$ may not be very cost-effective. The Web site Angiocalc.com allows the endovascular surgeon to calculate the packing attenuation of the aneurysm according to the number and kind of coils used.

The high recurrence rate of larger aneurysms after coil treatment may be, in large part, due to the low packing attenuation achievable as aneurysms increase in size. ${ }^{4}$ Detachable coils may be associated with a high recurrence rate with treatment of large cerebral aneurysms because simple geometric issues preclude achieving a high packing attenuation in most cases. While coils with complex shapes can help in forming a basket for the initial coil, it is not clear whether they augment packing attenuation significantly. ${ }^{9,10}$ The softness of the coils can also affect the packing attenuation achievable. Packing attenuation certainly has a direct relationship to the volume of each coil added, which is independent of coil shape or softness. Given the limited length and volume of coil that can technically still be inserted into the aneurysm at the final stages of coil embolization and the potential complications of aggressively pushing the last coil, these last coils may add little to the overall packing attenuation of the aneurysm.

Disclosures: David Kallmes receives research support from NFocus, MicroVention, Chestnut Medical, Micrus, Sequent, and eV3. Harry Cloft receives research support (including provision of equipment or materials) from Mindframe, Cordis, and MicroVention. He was a central reader for films for the PRIISM study sponsored by Mindframe, the enrolling center for the SAPPHIRE trial sponsored by Cordis, and the enrolling center for the Gel the Neck Trial sponsored by MicroVention. He was a consultant for Medtronic/Kyphon, in which capacity he served on the Data Safety and Monitoring Board for the KAVIAR trial.

\section{References}

1. Molyneux AJ, Kerr RS, Birks J, al. Risk of recurrent subarachnoid haemorrhage, death, or dependence and standardised mortality ratios after clipping or coiling of an intracranial aneurysm in the International Subarachnoid Aneurysm Trial (ISAT): long-term follow-up. Lancet Neurol 2009;8:427-33

2. Raja PV, Huang J, Germanwala AV, et al. Microsurgical clipping and endovascular coiling of intracranial aneurysms: a critical review of the literature. $\mathrm{Neu}$ rosurgery 2008;62:1187-202, discussion 1202-03

3. Molyneux A, Kerr R, Stratton I, et al. International Subarachnoid Aneurysm Trial (ISAT) of neurosurgical clipping versus endovascular coiling in 2143 patients with ruptured intracranial aneurysms: a randomised trial. Lancet 2002;360:1267-74

4. Molyneux A, Kerr R; Stratton I, et al, for the International Subarachnoid Aneurysm Trial (ISAT) Collaborative Group. International Subarachnoid Aneurysm Trial (ISAT) of neurosurgical clipping versus endovascular coiling in 2143 patients with ruptured intracranial aneurysms: a randomized trial. $J$ Stroke Cerebrovasc Dis 2002;11:304-14

5. Cloft HJ, Kallmes DF. Aneurysm packing with HydroCoil Embolic System versus platinum coils: initial clinical experience. AJNR Am J Neuroradiol 2004;25:60-62

6. Sluzewski M, van Rooij WJ, Slob MJ, et al. Relation between aneurysm volume, packing, and compaction in 145 cerebral aneurysms treated with coils. Radiology 2004;231:653-58. Epub 2004 Apr 29

7. Kawanabe Y, Sadato A, Taki W, et al. Endovascular occlusion of intracranial aneurysms with Guglielmi detachable coils: correlation between coil packing density and coil compaction. Acta Neurochir (Wien) 2001;143:451-55

8. Campi A, Ramzi N, Molyneux AJ, et al. Retreatment of ruptured cerebral aneurysms in patients randomized by coiling or clipping in the International Subarachnoid Aneurysm Trial (ISAT). Stroke 2007;38:1538-44. Epub 2007 Mar 29

9. Piotin M, Spelle L, Mounayer C, et al. Intracranial aneurysms: treatment with bare platinum coils-aneurysm packing, complex coils, and angiographic recurrence. Radiology 2007;243:500-08

10. van Rooij WJ, Sluzewski M. Packing performance of GDC 360 degrees coils in intracranial aneurysms: a comparison with complex orbit coils and helical GDC 10 coils. AJNR Am J Neuroradiol 2007;28:368-70 